\title{
La responsabilidad de la convicción: el pacifismo cristiano
}

ANTONIO GonZÁLEZ

Fundación Xavier Zubiri

Resumen: En los debates éticos y políticos, es frecuente apelar a la "responsabilidad" para justificar decisiones que parecen atentar contra ciertos valores morales. Este tipo de apelaciones son frecuentes cuando se trata de justificar el uso de la violencia.En este texto se analiza la diferencia entre la llamada "ética de la convicción" y la "ética de la responsabilidad". En este contexto, se harán algunas consideraciones sobre la doctrina tradicional de la "guerra justa" y la situación del pacifismo cristiano originario.

Abstract: The appeal to "responsability" in order to justify decisions that seem to attempt against certain moral values is frequent on the ethical and political debates. Such appeals are frequent when someone tries to justify the use of violence. In this paper the difference between the "ethics of conviction" and the "ethics of responsability" is analysed. In this context, some considerations on the traditional doctrine of "fair war" and the situation of the original Chistian pacifism will be made.

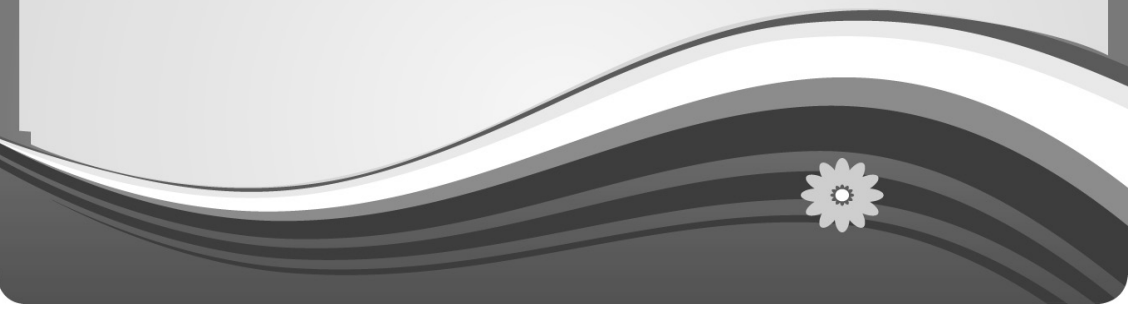

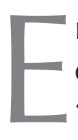

n los debates éticos y políticos, es frecuente apelar a la "responsabilidad" para eludir comportamientos que podrían ser éticamente vinculantes o para justificar decisiones, a veces brutales, que parecen atentar contra ciertos valores morales. Este tipo de apelaciones son frecuentes cuando se trata de justificar el uso de la violencia. Desde un punto de vista "responsable" se podría afirmar, por ejemplo, la necesidad de utilizar la violencia para defender el sistema político democrático, o para asegurar el acceso al petróleo, para que una determinada revolución social triunfe, etc. Desde este punto de vista, los pacifistas serían personas irresponsables que podrían permi- 
tirse el lujo de rechazar la violencia precisamente porque hay instituciones y personas "responsables" que defienden, mediante la violencia, sistemas políticos en los que es posible la objeción de conciencia, o la crítica a los esfuerzos bélicos.

En estas páginas analizaremos brevemente la diferencia entre la
Ilamada "ética de la convicción" y la "ética de la responsabilidad", atendiendo especialmente a la postura pacifista como muestra de lo que podríamos Ilamar "una convicción responsable". En este contexto, haremos algunas consideraciones sobre la doctrina tradicional de la "guerra justa", y trataremos de situar el pacifismo cristiano originario.

\section{Responsabilidad y convicción}

La distinción entre estos dos tipos de ética proviene de la filosofía de Max Scheler, quien distinguía entre "ética del éxito" (Erfolgsethik) y "ética de la convicción" (Besinnungsethik). En el planteamiento de Scheler, esta distinción tiene la función de defenderse contra una posible acusación kantiana, según la cual toda ética material sería una ética de los resultados, mientras que la verdadera ética sería siempre una ética de las intenciones. Al introducir el concepto de "convicción" (Besinnung), a diferencia de la mera intención (Absicht), Scheler quiere mostrar que las convicciones están orientadas a valores, es decir, a contenidos concretos, que son precisamente los que caracterizan su proyecto de una "ética material", en el sentido de una ética con contenidos. Estos valores, sin embargo, no se identifican con los resultados. Para Scheler, como para Kant, es absurdo hacer depender el relieve moral de una conducta práctica de un cálculo de los resultados probables de la misma, de modo que la convicción tiene en sí misma una materia de valor independiente del resultado de las acciones.

La distinción fue retomada por el sociólogo Max Weber en una conferencia del año 1919, titulada "La política como vocación", pero con una intención radicalmente inversa a la de los filósofos. Para Weber, el caos social y político de esos años en Alemania estaba muy directamente ligado a las posiciones extremas de quienes tomaban decisiones radicales, basados en sus convicciones, sin tener en cuenta los resultados de sus acciones. No se trataba, para Weber, de reducir la ética a sus resultados, pero sí de ser responsable de los mismos. Por eso Weber habla de "ética de la responsabilidad" (Verantwortungsethik), y no de "ética de los resultados", como había hecho Scheler. Para Weber, la ética de la responsabilidad, a diferencia de la ética de la convicción, tendría en cuenta las consecuencias de las propias acciones, privilegiando por tanto 
aquellas actuaciones que tuvieran verdaderas posibilidades de éxito. Así, por ejemplo, un político no sería responsable si se gastara todo el presupuesto disponible en medidas sociales que, aunque resolvieran necesidades inmediatas, no garantizarían la desaparición de esas necesidades a largo plazo. El gasto del presupuesto disponible podría tener como consecuencia la aparición de necesidades mayores durante los años siguientes. Del mismo modo, un político "responsable" no puede actuar llevado por convicciones pacifistas, sino que tendrá que recurrir a la violencia para combatir el crimen, o para defender las fronteras de su estado.

El mismo Max Weber reconocía que la ética de la convicción no estaba carente de responsabilidad, del mismo modo que la ética de la responsabilidad era portadora de convicciones. Sin embargo, su concepción negativa de la ética de la convicción le conducía a definirla más bien por la pretensión de justificar la acción moral por su valor intrínseco, sin consideración de los resultados. Quien actúa en el marco de la ética de la convicción no se preocuparía por los resultados, dejándolos, por ejemplo, en manos de Dios. En cambio, para Weber es claro que la ética de la responsabilidad tiene convicciones. Son precisamente esas convicciones las que le permiten preferir ciertos resultados en lugar de otros. Así, por ejemplo, cuando el político ordena una determinada acción violenta, como la represión de una manifestación o el inicio de una guerra, lo hace responsablemente cuando entiende que, si no realizara tales acciones, se causarían daños mayores desde un punto de vista ético, como, por ejemplo, la pérdida de un mayor número de vidas humanas. Este tipo de responsabilidad presupone, por tanto, una convicción previa sobre el valor de la vida humana, que es justamente lo que nos permitiría actuar de una manera "responsable".

\section{La "guerra justa"}

La doctrina de la "guerra justa" podría considerarse en principio como un ejemplo típico de ética de la responsabilidad. Los orígenes de este planteamiento se pueden encontrar en el filósofo romano Cicerón, pero su desarrollo tuvo lugar en el contexto del pensamiento medieval. Mientras que para la mentalidad pagana la guerra era algo casi natural, el cristianismo tuvo de algún modo que enfrentarse al contraste entre las convicciones pacifistas de sus orígenes y la alianza creciente de la iglesia con el imperio romano, especialmente a partir del siglo IV. De este modo, el primer gran teórico cristiano de la "guerra justa", Agustín de Hipona, reconocía el valor de las actitudes pacíficas, tanto en la vida privada como la vida monástica, pero recla- 
maba el derecho del imperio romano a defenderse, y la obligación de los "laicos" cristianos a contribuir a esa defensa. De hecho, Agustín de Hipona terminó defendiendo incluso la obligación de las autoridades imperiales de perseguir a los cristianos cismáticos o heterodoxos.

La teología medieval y moderna fue construyendo la doctrina de la "guerra justa", con observaciones interesantes. Tomás de Aquino analizó la acción violenta distinguiendo en ella un "doble efecto". La acción violenta, por una parte, logra que la persona agredida defienda la propia vida cuando tiene derecho a ello. De hecho, según Tomás, uno está más obligado a defender la propia vida que la vida ajena. Pero, por otra parte, la acción violenta defensiva tiene como un segundo efecto el daño o incluso la muerte del ofensor. Ahora bien, uno puede desear solamente lo primero (la defensa de la propia vida), tomando lo segundo (la muerte del ofensor) como una consecuencia inevitable, aunque no perseguida por sí misma. Tomás insistió en que, en estos casos, es necesario que haya una proporcionalidad entre los efectos que se persiguen y los efectos no deseados. No sería proporcional, por ejemplo, la eliminación de toda una familia, o de toda una aldea, para defenderse de un solo agresor. En esta perspectiva, se entiende la adhesión de Tomás a la doctrina de la "guerra justa". No toda guerra sería justa, pero una guerra determinada puede serlo si cumple ciertas condiciones. Para Tomás, la guerra puede ser justa cuando es iniciada por una autoridad legítima, cuando su causa es justa, y cuando la intención de los beligerantes es recta.

Posteriormente, otros pensadores como Francisco de Vitoria, añadieron otros motivos legítimos para la guerra, teniendo especialmente en cuenta las condiciones de la conquista de América. Para Vitoria, el derecho a la libre circulación de las personas (incluyendo el derecho al comercio), el impedimento de la predicación del evangelio, la imposición de la idolatría por fuerza a los recién convertidos, el conflicto del papa con líderes indios convertidos al cristianismo, la tiranía de los gobernantes paganos, la aceptación por la mayoría de los indios del gobierno de los españoles, o las obligaciones impuestas por alianzas establecidas con grupos amigos serían motivos válidos para que la "autoridad legítima" (el rey de España) podría iniciar una "guerra justa". En cambio, otros motivos aducidos para justificar la conquista, como el presunto dominio universal del emperador español, la autoridad universal del papa, el derecho del descubridor, el rechazo personal de la fe, los pecados de los indios, el rechazo del señorío de los españoles, o una donación especial de Dios no serían, según Vitoria, títulos legítimos para emprender una guerra. 
En el campo protestante, las nuevas iglesias salidas de la Reforma mantuvieron la estructura territorial del catolicismo, y fueron apoyadas por los respectivos gobiernos de las naciones emergentes en Europa. A pesar de algunas dudas iniciales, los teólogos mantuvieron la doctrina de la "guerra justa", aunque haciendo algunas observaciones interesantes. Así, por ejemplo, Lutero entendía que uno puede renunciar "evangélicamente" a la propia defensa, pero no puede renunciar a defender a su prójimo. De hecho, Lutero apoyó decididamente la represión de las revueltas campesinas por los príncipes alemanes, a pesar de que los campesinos, por su parte, justificaban su rebelión apelando a su ganada libertad para leer e interpretar la Escritura. Otros pensadores protestantes, como Hugo Grocio, en el contexto de las guerras de religión europeas, introdujeron algunas reflexiones importantes en el marco de la doctrina de la "guerra justa", señalando por ejemplo que las "guerras preventivas", basadas en la creciente potencia del adversario, nunca son legítimas. También reflexionó Grocio sobre los derechos de los vencidos, señalando que a éstos no se les pueden imponer más cargas que las derivadas de las agresiones originalmente cometidas, o de los daños sufridos por el vencedor.

Con la excepción de cristianos como Erasmo de Rotterdam o los anabautistas del siglo XVI, la doc- trina de la "guerra justa" dominó el pensamiento de las iglesias "establecidas" hasta épocas muy recientes. En la actualidad, el catecismo oficial de la iglesia católica mantiene esa doctrina, aportando diversos criterios, tomados de la tradición, para discernir entre las guerras justas, que serían siempre de carácter defensivo, y las guerras injustas. Así se mencionan condiciones tales como la presencia de daños duraderos, graves y ciertos causados por el agresor, el agotamiento de todos los medios alternativos, las condiciones serias de éxito, y la proporcionalidad entre los daños causados por el uso de las armas y los males que se pretenden evitar.

Sin embargo, el siglo XX conoció algunas importantes novedades respecto a esta doctrina. En primer lugar, el papa Pablo VI, en su encíclica Populorum progressio, Ilevó a cabo lo que podemos considerar una "ampliación" del derecho de la "guerra justa", aplicando los criterios tradicionales al caso de una insurrección popular. Ante una tiranía evidente y prolongada, que dañase los derechos fundamentales de las personas y el bien común de los ciudadanos de un país, se podría considerar legítimo un levantamiento popular. De alguna manera, el criterio de la "autoridad legítima" se aplicó en el sentido de una soberanía última del pueblo. En cualquier caso, las implicaciones revolucionarias de esta doctrina, y su uso en el ámbito de la teología 
de la liberación, posiblemente han sido los motivos por los que no ha vuelvo a aparecer en los documentos oficiales de la iglesia católica.

En segundo lugar, en una línea en cierto modo opuesta, el papa Juan Pablo II se opuso a la segunda guerra del Golfo, indicando mediante un enviado especial al presidente Bush, que una acción militar, sin el apoyo de las Naciones Unidas, sería injusta. El hecho es significativo, porque, curiosamente, a lo largo de los siglos de historia, la doctrina de la "guerra justa" nunca había servido para declarar explícitamente que una guerra fuera injusta, a pesar de los muchos criterios disponibles para ello. De hecho, las autoridades de las iglesias establecidas de los distintos países "cristianos" siempre entendieron que las respectivas campañas militares de sus ejércitos eran "justas", aunque combatieran contra otro ejército "cristiano".

Finalmente, también en el ámbito de las doctrinas católicas oficiales u oficiosas, ha ido tomando cada vez más fuerza la idea de que una guerra moderna difícilmente podría ser considerada como justa, debido a su carácter masivo, y a las consecuencias devastadoras que tiene siempre para la población civil.

Nótese de todos modos, que, en estos casos, la doctrina de la "guerra justa" no cambia en su contenido fundamental. En prin- cipio, bajo ciertas condiciones, se piensa que podría haber guerras justas. Lo que cambia es más bien la aplicación de la doctrina. Determinadas guerras, o incluso todas, comienzan a calificarse de modo más o menos explícito como injustas, por no cumplir las condiciones propias de una "guerra justa". Esto se debe a la aplicación de criterios clásicos como la existencia de una autoridad legítima (en este caso las Naciones Unidas), o la debida proporcionalidad entre los bienes que se quieren proteger con la guerra y los daños que inevitablemente se van a causar.

Sería importante pensar hasta qué punto la doctrina de la "guerra justa", en su versión eclesiástica, encaja plenamente en el marco de la ética de la responsabilidad. Desde luego, los criterios considerados por la tradición pretenden justamente un uso responsable de la violencia. Ahora bien, la responsabilidad por el resultado de nuestras acciones nos podría llevar a pensar que en ciertas situaciones, al menos en teoría, sería irresponsable no actuar de una manera violenta. En el caso de que una guerra sea justa, parece que no ir a la guerra sería injusto. Podemos preguntarnos entonces si, desde el punto de vista de la doctrina de la "guerra justa", toda posición pacifista ante una "guerra justa" sería entonces una posición éticamente condenable. Al menos, se podría pensar que una parte de la población actuaría 
incorrectamente si no fuera a la guerra: por ejemplo, los militares, o todas las personas que han jurado la defensa de su país. Sin embargo, no está claro que estas obligaciones se extiendan a toda la población. De hecho, los defensores de la "guerra justa" han señalado que los clérigos deberían de estar exentos del servicio militar. Algo que no deja de ser sorprendente, pues parecería que los clérigos tendrían que ser los primeros en actuar "justamente". Parecería haber, en la doctrina de la "guerra justa", una cierta mala conciencia ante la misma, tal vez residuo de las convicciones pacifistas del cristianismo primitivo.

De este modo, una aplicación estricta de la ética de la responsabilidad podría llevarnos a pensar que el pacifismo, incluyendo el de los clérigos u otros sectores de la población, sería simplemente irresponsable. ¿Es esto así? Para estudiarlo tenemos que echar un vistazo más detenido a la responsabilidad.

\section{Análisis de la responsabilidad}

1) La ética de la responsabilidad habla de un "dar cuentas" de las propias acciones, a diferencia de olvidarse de las consecuencias que esas acciones tendrán, o de dejarlas en las manos de Dios. Esto nos pone de relieve un aspecto importante de esta ética, que es su dimensión de poder. La ética de la responsabilidad presupone una capacidad del sujeto ético para controlar con algún grado de certeza cuáles serán las consecuencias previsibles de las acciones. Por eso se trata precisamente de una ética que Weber adjudica precisamente al político, y que, por supuesto, se puede extender a otras personas, como aquellos que aconsejan a los políticos, o, en general, todos aquellos que disponen del poder suficiente para ejercer algún tipo de control sobre las consecuencias de sus acciones. En este sentido, es perfectamente comprensible que el abandono del pacifismo, al menos de una manera generalizada, venga a coincidir, en la historia del cristianismo, con su llegada al poder en el siglo IV, en virtud de su alianza con el imperio romano.

2) En segundo lugar, la responsabilidad alude obviamente a un "responder". Este "responder" o dar cuentas implica, en el caso de la ética política, la idea de algún tipo de "democracia", en el sentido más amplio de la expresión. El político responsable, por ejemplo, es aquél que está dispuesto a dar cuentas a los ciudadanos de las consecuencias de sus acciones. Cuando, por ejemplo, deniega unas ayudas para cubrir necesidades inmediatas, cuando permite un proyecto industrial que puede ocasionar daños ecológicos, o cuando se involucra en una guerra, lo hace con la conciencia de que otras alternativas 
tendrían consecuencias que serían todavía peores que las que previsiblemente tendrán sus acciones, y que los ciudadanos ante los que es responsable tendrían más dificultades en aceptar.

3) En tercer lugar, el político "responsable" cuenta con la existencia una serie de convicciones compartidas entre los ciudadanos a los que tiene que dar cuentas. Por eso, la toma de decisiones tiene lugar en función de esas convicciones. De este modo, se privilegian las medidas que tienen posibilidades de producir resultados más acordes con las convicciones compartidas por aquéllos ante los que se tiene que responder. Por supuesto, estas convicciones pueden ser de diverso tipo, y no siempre serán altruistas, ni mucho menos. Así, por ejemplo, el político siempre tendrá que tener en cuenta que los ciudadanos posiblemente valoren sus propios intereses, incluyendo el interés en la preservación de la propia vida, más que los intereses de los miembros de otras sociedades, incluyendo el interés de esos miembros de otras sociedades en preservar la propia vida.

Esto ya nos muestra algunas dificultades de la ética de la responsabilidad.

a) En primer lugar, una crítica frecuente de la misma ha consistido en indicar el carácter impredecible que frecuentemente pueden tener los resultados de nuestras acciones. Sin embargo, desde el punto de vista de la ética de la responsabilidad hay una respuesta fácil a esta objeción. Uno es responsable solamente de las consecuencias previsibles de los propios actos, y no de las consecuencias imprevisibles. Desde un punto de vista ético, lo que se puede afirmar, en todo caso, es que la responsabilidad incluye una obligación de conocer, en la medida de lo posible, todas las consecuencias que pueden derivarse de nuestras acciones.

b) Una segunda dificultad de la ética de la responsabilidad habría que situarla en su dimensión "democrática". El político, en una democracia, debería ser responsable ante todos los ciudadanos. Pero, de hecho, su responsabilidad suele restringirse a dar cuentas ante aquellas personas o instancias que tienen mayor capacidad de cuestionar efectivamente al político por los resultados de sus acciones. De este modo, la tendencia del político "responsable" al calcular las consecuencias de sus acciones será calcular también quiénes van a ser los que le van a exigir cuentas de las mismas. Así, por ejemplo, podría suceder que una minoría que no va a la guerra (por ser más ricos) sea sin embargo la minoría que más dispuesta esté a exigir al político un comportamiento bélico, debido a sus intereses económicos particulares. 
c) Esto indica, en tercer lugar, que la ética de la responsabilidad parece estar caracterizada por una tendencia hacia una disolución de los criterios morales en mero pragmatismo. Aunque el político puede tener convicciones morales, no son sus convicciones propias las que deciden el curso de las acciones "responsables", sino los criterios de aquellos ante los que el político tiene que responder. Aunque éstos no fueran los más poderosos, sino los ciudadanos en su conjunto, solamente en el caso de que la mayoría de esos ciudadanos estuvieran guiados por criterios éticos haría posible que el político en cuestión también lo estuviera. Lo cual significa, en definitiva, que las convicciones propias se sacrifican a criterios que van más allá de la moralidad. Parecería haber en la ética de la responsabilidad una tendencia, no fácilmente evitable, no sólo a tener en cuenta los resultados de las propias ac- ciones, sino a que estos resultados sean finalmente los que justifican nuestras acciones.

Por supuesto, el político podría optar por responder, no ante sus electores o ante los grupos de poder que lo sostienen, sino "ante su propia conciencia". En este caso, las diferencias entre la ética de la convicción y la ética de la responsabilidad comienzan a diluirse, al menos si se admite que, como veremos, en la ética de la convicción también hay lugar para la responsabilidad. En cualquier caso, las críticas usuales a la ética de la responsabilidad solamente apuntan hacia su dificultad más importante, sin llegar a formularla plenamente, y que tendremos que mostrar más adelante. Pero antes de considerar esta dificultad, hemos de preguntarnos si verdaderamente la ética de la convicción está desprovista de responsabilidad.

\section{La convicción responsable}

Como vimos, la caracterización usual de la ética de la convicción consiste en señalar que ella no tiene en cuenta las consecuencias de las propias acciones. Ahora bien, ¿qué se entiende por "consecuencia" o por "resultado" de una acción? Toda acción pretende algo, o culmina en algo. $\mathrm{Y}$ eso que pretende, o en lo que culmina, es precisamente un resultado. Si, por ejemplo, deseo evitar convertirme en el asesino de otro ser humano, y lo evito efecti- vamente, esto es ya un "resultado" de la acción. Por supuesto, otro "resultado" de esa misma acción puede ser que ese ser humano, si yo no lo he matado, me asesine a mí, o asesine a otras personas. Como bien vio Tomás de Aquino, una acción puede tener múltiples resultados. Lo que sucede es que estos resultados tienen que ser queridos cuando actuamos. No podemos decir que, al disparar un fusil, lo que queremos es la paz, pero la acción tiene 
el "doble efecto" de atravesar el cráneo de un enemigo. Al disparar, queremos también atravesar el cráneo de un enemigo. Precisamente por eso, la ética de la convicción, lejos de ignorar los resultados de nuestras acciones, quiere tener en cuenta todos los resultados. Al hacerlo entiende que unos resultados previsibles en el futuro no pueden cambiar la índole moral de los resultados inmediatamente queridos. $Y$ es que el querer es un carácter del acto moral que es inseparable de lo inmediatamente querido.

Esto no quiere decir que la ética de la convicción prescinda de los resultados ulteriores, no inmediatamente queridos, de las propias acciones. Esos resultados también pertenecen también a la acción. Sin embargo, estos resultados son más ricos y complejos de lo que la "ética de la responsabilidad" suele sospechar. Veamos esto más detenidamente.

1) Podríamos decir, por ejemplo, que la ética de la convicción tiene una responsabilidad "humanista", en el sentido de pensar que cualquier sacrificio de vidas humanas que sea justificado en función de los resultados ulteriores de nuestras acciones tiene también como resultado una devaluación general de la vida humana. Esto se aplica claramente en todos los casos en que las vidas humanas son sacrificadas (por violencia o por omisión) en función de cualquier resultado que sea distinto de la preservación de la vida humana misma. Pero también se podría aplicar incluso en los casos en los que se hace un "cálculo" de vidas humanas, sacrificando ciertas vidas humanas para salvar otras. Estos cálculos, en la medida en que trivializan el homicidio, convirtiéndolo en parte de la cultura, o incluso en un valor heroico, también podrían tener como resultado una devaluación de la vida humana en general. Como ya señalaba el Talmud, quien asesina a una persona de algún modo asesina a toda la humanidad. No sólo eso. Los cálculos realizados en términos de vidas humanas suelen llevar a cabo una diferencia entre las vidas de "ellos" frente a "nuestras" vidas, de tal modo que un resultado de tales procesos de decisión es previsiblemente un refuerzo del nacionalismo, el racismo o la xenofobia. Además, los políticos a los que se les adjudica el derecho de realizar tales cálculos quedan situados en una posición de decidir sobre las vidas humanas, de tal modo que un resultado previsible de los mismos es el refuerzo de las tendencias autoritarias, militaristas, dictatoriales, etc.

2) Estas consideraciones nos ponen ante un segundo tipo de responsabilidad que caracteriza, o puede caracterizar, a la ética de la no-violencia. Es lo que podemos llamar la responsabilidad "alternativa". Como vimos, la doctrina de la "guerra justa" nos invita sensatamente a tener en cuenta las propias 
posibilidades de éxito cuando, por ejemplo, emprendemos el uso de la violencia para derrotar a una monstruosa dictadura, etc. Ahora bien, es importante darse cuenta que, cuando pretendemos enfrentar la violencia con la violencia, un requisito esencial para tener éxito es el de tener una capacidad destructiva que sea razonablemente superior a la capacidad destructiva del enemigo. $Y$ esto significa que el resultado previsible de tales dinámicas es lo que podemos Ilamar la propia "monstruización". Uno tiene que terminar siendo muy parecido al agresor violento para poder triunfar sobre él. El resultado previsible es que uno asume los métodos, los valores, e incluso los fines del agresor. Esto es algo importante, incluso cuando la primera agresión es una "violencia institucionalizada". La respuesta violenta a la misma tiene muchas posibilidades de terminar institucionalizando la misma violencia que hizo posible la victoria. En cambio, la negativa a responder al opresor con los mismos medios violentos tiene como resultado previsible el desarrollo de vías alternativas de actuación que eviten una asimilación entre los agredidos y el agresor.

3) Esto nos conduce hacia un tercer tipo de responsabilidad, que puede estar presente en la ética de la convicción: es la que podemos llamar responsabilidad "anticipatoria". Cuando la ética de la responsabilidad justifica sus acciones presentes en función de sus resultados previsibles en el futuro, en realidad no abre nuevas vías hacia el porvenir. El resultado previsible de sus cálculos es la perpetuación de los modos de actuar que son usuales en el presente. En cambio, la ética pacifista, cuando renuncia a cualquier justificación pragmática de sus actuaciones, tiene como resultado previsible la muestra, ya en el presente, de que ya se puede vivir (e incluso morir) de otra forma. La mostración histórica, mediante una práctica individual y colectiva, de que otro mundo es posible es particularmente importante en una situación global caracterizada por la desesperanza. La ética pacifista, renunciando a justificarse por los resultados futuros de las acciones, tiene paradójicamente el resultado de anticipar un porvenir distinto del presente, convirtiéndose de este modo en "primicias" de una esperanza que puede ser visible incluso para quienes no tienen las propias convicciones. De alguna manera, la ética de la convicción tiene el resultado previsible de adelantar un porvenir distinto, y mejor, que el presente.

4) De ahí, en cuarto lugar, lo que podemos Ilamar la responsabilidad "poliárquica" de la convicción. Podemos decir que la ética pacifista, precisamente por no esperar una justificación de las propias acciones mediante unos resultados de los que podría dar cuenta ante el conjunto de la población, implica la existen- 
cia, y la permisión, de un pluralismo moral. Ciertamente, uno puede ser pacifista " $y$ " anarquista, en el sentido de rechazar la existencia de una institución, como el estado, que es esencialmente violenta. Como decía el mismo Weber, el estado es el monopolio de la violencia legítima en un territorio. Y, por tanto, es "vengador", tal como señalaban los primeros cristianos. Sin embargo, el anarquismo que pretende acabar con el estado no es la única posición posible. Se puede admitir, por ejemplo, la existencia del estado pensando que no todos tienen que tener necesariamente las propias convicciones pacifistas. En este caso, el resultado previsible de las actuaciones que se guíen por esas convicciones es la exigencia de una pluralidad, y la consiguiente diferenciación entre estado y sociedad. Uno no puede exigir que el estado sea pacífico (va contra su propia esencia como estado), pero sí puede exigir el derecho a no ser estado, ni a comportarse como el estado. El resultado previsible de las actuaciones de acuerdo a la convicción pacífica es, por tanto, el crecimiento del verdadero pluralismo ético.

Todo ello nos muestra que, paradójicamente, la negativa a justificar las propias acciones por sus resultados no es una dejación de la responsabilidad, sino un modo eminente de la misma. Hay, sin embargo, todavía una quinta forma de responsabilidad, que merece la pena analizar más detenidamente.

\section{La responsabilidad universal}

Para ilustrar un quinto tipo de responsabilidad, propio de la convicción, podemos comenzar refiriéndonos a una anécdota, que he recibido como auténtica, aunque lo que se pretende ilustrar no pende de su historicidad. Un joven perteneciente a los Amish (grupo religioso pacifista) es convocado a la oficina de reclutamiento de su país, para participar en una de las guerras emprendidas por Estados Unidos a lo largo del siglo XX. Cuando el joven afirma que sus convicciones cristianas le impiden matar a otra persona, es objeto de burlas por los militares y por los otros jóvenes que están siendo reclutados. Un oficial, enojado, le dice: "si todos fueran como tú, los comunistas ganarían la guerra y conquistarían el mundo". En ese momento, otro de los oficiales se siente movido a defender al joven, y contesta: "No, si todos fueran como él, no habría comunistas, ni guerras".

Es interesante observar que ambas afirmaciones tienen en cuenta "responsablemente" los resultados de las acciones. Y, curiosamente, ambas afirmaciones son verdaderas o, la menos, bastante verosímiles. $\mathrm{Si}$ todos fueran como el muchacho Amish, no habría modo de resistir a los enemigos. Los enemigos ven- 
cerían. Pero, por otra parte, también es verdad que, si todos fueran como el muchacho Amish, no habría enemigos. Cuando dos afirmaciones, aparentemente contradictorias, son verdaderas al mismo tiempo, los filósofos kantianos nos dirían que estamos ante un "paralogismo". Sería un paralogismo, no de la razón pura, sino de la razón práctica. En un paralogismo, la aparente contradicción se resuelve cuando se muestra que un mismo término se ha usado en sentidos diversos, de modo que no hay verdadera contradicción.

Pues bien, en nuestras dos frases, el punto crucial está en el uso de la palabra "todos". En la primera frase, "todos" ("si todos fueran como tú, los comunistas ganarían la guerra") se refiere, en este caso, a los ciudadanos de los Estados Unidos, y tal vez de las naciones aliadas. $Y$ es verdad que, si todos los reclutas de esas naciones se negaran a pelear, los enemigos vencerían. En la segunda frase, "todos" ("si todos fueran como tú, no habría guerras") se refiere a todos los seres humanos, de todas las partes del mundo. Y, evidentemente, si todos fueran como el muchacho Amish, no habría guerras. Por eso las dos afirmaciones pueden ser verdaderas al mismo tiempo, sin ser contradictorias: están hablando de distintos grupos de personas. Es importante observar también que ambas frases son condicionales: "todos" tendrían que ser como el muchacho Amish, por más que en realidad se cuenta con que, de momento, "todos" no se van a comportar como él. Sin embargo ambas frases consideran las posibles consecuencias de la generalización del comportamiento del muchacho Amish. Por eso, ambas frases hablan responsablemente, pero su responsabilidad cubre distintos ámbitos de la humanidad. Mientras en la primera, la responsabilidad distingue entre "nosotros" y "ellos", en la segunda frase la responsabilidad incluye verdaderamente a "todos", a toda la humanidad.

La responsabilidad de la convicción pacífica es una responsabilidad verdaderamente universal, mientras que la "ética de la responsabilidad" no alcanza el nivel de universalidad que, al menos desde cierto punto de vista, sería exigible para toda ética. Cuando, desde el punto de vista de la ética de la responsabilidad, se está denegando la ayuda a las regiones que padecen hambruna, o se están apoyando proyectos potencialmente dañinos desde el punto de vista ecológico, o se está emprendiendo una guerra, lo que sucede normalmente en estos casos es que la "responsabilidad" del político es una responsabilidad limitada solamente a ciertos grupos de personas, como pueden ser los habitantes de ciertos países, a diferencia de los países "enemigos", o a las generaciones presentes, evitando responder ante las generaciones futuras, que sufrirán las consecuencias de los daños ecológicos del presente. 
Este carácter universal de la responsabilidad inscrita en la ética de la convicción nos hace preguntarnos no sólo hasta qué punto la llamada "ética de la responsabilidad" es verdaderamente una ética que pueda pretender universalidad, sino también nos muestra que solamente la perspectiva de la ética de la convicción puede hacer justicia a la idea de una básica igualdad de todos los seres humanos. De este modo, la ética de la convicción enlaza con las aspiraciones hacia algo así como una "democracia mundial" en la que todos los habitantes del planeta 8puedan tomar decisiones colectivas, en pie de igualdad, sobre los asuntos que les conciernen a todos.

\section{El pacifismo de Jesús}

Las consideraciones anteriores nos sirven también para situar el pacifismo cristiano. Aunque tal vez sería mejor hablar del "pacifismo de Jesús", ya que los cristianos, como decía Gandhi, son los únicos que parecen no haber captado que Jesús era pacifista. En cualquier caso, el pacifismo del fundador del cristianismo se inscribe en las tradiciones de Israel. De hecho, son conocidos, en el siglo I, con independencia del cristianismo, el pueblo judío ejerció en ocasiones la resistencia pacífica, con notable éxito, frente a las autoridades romanas. De ahí que, para entender el planteamiento de Jesús, sea esencial insertarlo en su contexto judío.

1) En este trasfondo hay que situar la responsabilidad "humanista", tal como es percibida en la religión de Israel. La idea de creación implica, en las tradiciones bíblicas, una radical "des-divinización" del universo. La idea de una creación por la palabra implica una diferencia radical entre el Creador y las criaturas, que no pueden ser consideradas como una emanación de la divinidad, ni como una parte de ella. Las realidades que, en el contexto religioso semita, eran consideradas como divinas (sol, luna, astros), son vistas como meras criaturas, al servicio del ser humano ("lumbreras" en el cielo). El ser humano es criatura pero, a diferencia de toda otra realidad, es "imagen y semejanza" de Dios. Esto significa que, así como el Dios bíblico es distinto de su creación, el ser humano no está destinado a ser sometido a ninguno de los poderes de este mundo. $Y$ esto es algo que se afirma de "Adán", es decir, de todo ser humano (adam en hebreo). No hay ninguna realidad creada que pueda ser considerada como una instancia superior al ser humano, al que éste pudiera ser sacrificado.

2) En segundo lugar, Jesús apela a las tradiciones judías sobre el "reino de Dios", las cuales de alguna manera resumen el núcleo de la auto-comprensión de Israel en el conjunto de las naciones. En esta auto-comprensión, Israel está 
llamado a ser un pueblo distinto, para mostrar a las demás naciones qué es lo que sucede cuando Dios gobierna directamente sobre un pueblo ("reino de Dios"), y le otorga una "instrucción" (torah) para vivir en justicia. Esta Torah, destinada a evitar el sometimiento del ser humano a los poderes de este mundo, incluía múltiples medidas para asegurar la igualdad fundamental de todos los israelitas. De este modo, los deudas habían de ser canceladas períodicamente, los esclavos liberados, y las personas habrían de volver periódicamente a poseer sus tierras ancestrales, evitando la formación de grandes diferencias sociales. La apelación de Jesús al reino de Dios implica la asunción de estas tradiciones, tal como lo entendió también la iglesia cristiana primitiva. Es lo que hemos Ilamado la "responsabilidad anticipatoria". Los seguidores de Jesús han de mostrar a sus congéneres la posibilidad de un mundo distinto. Por eso el reino de Dios no ha de ser vivido solamente como una utopía de futuro, sino también como una realidad presente.

3) Estas tradiciones implican, en tercer lugar, una perspectiva que encaja en lo que hemos llamado la responsabilidad "poliárquica". La idea de un "reinado de Dios", lejos de legitimar la monarquía en Israel, tuvo más bien la función opuesta. Desde el punto de vista judío, si Dios es Rey, no tiene mucho sentido que otros lo sean. Si Dios es amo, la esclavitud queda cues- tionada. Si Dios es "Señor de los Ejércitos", no tiene mucho sentido acumular poderío militar, etc. La soberanía de Dios tiene como resultado el cuestionamiento de otros poderes, que ya no pueden aspirar a regir completa y totalmente al ser humano. El ser humano, bajo el reinado de Dios, puede quizás aceptar otros soberanías, pero solamente de una forma parcial. En caso de conflicto, tiene que obedecer a Dios antes que a los hombres.

Es interesante observar que, en el planteamiento de Jesús, continuado por el cristianismo primitivo, el pueblo de Dios habría de configurarse de una forma no estatal, a diferencia de lo que es habitual entre las "naciones". Esto implica obviamente la posibilidad de que las comunidades cristianas convivan bajo distintos estados, manteniendo sin embargo una independencia relativa respecto a los mismos, y contribuyendo de este modo a la tolerancia de la pluralidad. Obviamente, el cristianismo solamente pudo desempeñar esta tarea en aquellas circunstancias en las que se mantuvo como un grupo de pertenencia libre. Cuando el cristianismo se identificó con el conjunto de la sociedad, esta responsabilidad poliárquica no se pudo ejercer de forma plena, y el cristianismo participó en distintas formas de intolerancia. Ni que decir tiene que, en estos casos, el pacifismo cristiano tuvo que ser sustituido por fórmulas más bien paganas, como las propias de la "guerra justa". 
Digamos de paso que esta característica del pacifismo de Jesús le diferencia fuertemente del pacifismo del Mahatma Gandhi. El pacifismo de Gandhi se desarrolla en el contexto de la fundación de un estado, el estado de la India. Y el estado implica el monopolio de la violencia legítima en un determinado territorio. De ahí que el pacifismo de Gandhi tenga paradójicamente la función de minimizar el uso de la violencia durante un proceso de transferencia del monopolio de la misma entre el imperio británico y los nuevos gobernantes autóctonos. En cambio, el pacifismo de Jesús se constituye en la renuncia explícita, por parte de él y de su grupo, a la configuración de Israel como un estado. De ahí que Jesús pueda aspirar a una universalidad radical, que desaparecería en cualquier planteamiento meramente nacionalista. $Y$ de ahí también su peculiar renuncia a la violencia. Algo que entraña otra paradoja: Jesús es reconocido como Mesías por sus seguidores, y el término "Mesías" no tiene inicialmente significados místicos o trascendentes, sino primeramente políticos: el Mesías es el rey ungido de Israel. Pero este rey, poniéndose "de parte de Dios" ("a su derecha"), cuestiona la configuración estatal de Israel, como antaño lo habían hecho los profetas, en nombre del mismo Dios.

4) En el planteamiento pacífico de Jesús encontramos también lo que hemos Ilamado la "responsabilidad alternativa", que bien se puede colegir de todo lo anterior. En el planteamiento del "Sermón de la montaña", Jesús motiva el amor a los enemigos aludiendo, de forma positiva, a la imitación del Padre celestial, que hace salir el sol sobre justos e injustos, $y$, de forma negativa, en la insuficiencia de que el pueblo de Dios reproduzca el mismo comportamiento de los paganos. También los paganos aman a los que les aman: no tiene ninguna "gracia" hacer lo mismo que ellos. En un mundo regido por la violencia, la convicción pacifista tiene como objetivo "responsable" la introducción de nuevos criterios de comportamiento, que puedan tener como resultado una praxis renovada.

Precisamente muchos de los ejemplos puestos por Jesús tienen como objetivo la introducción de una diferencia práctica. Quien es golpeado en la mejilla derecha, es normalmente alguien golpeado con el reverso de la mano, lo cual constituye un gesto de desprecio, como el que podría hacer un terrateniente con sus jornaleros o un amo con sus esclavos. El poner la otra mejilla, la mejilla izquierda, tiene por resultado previsible una cierta confusión de la parte opresora, que se ve obligada a reflexionar. Del mismo modo, quien se queda desnudo en un tribunal ejerce, en la cultura hebrea, una especie de vergüenza para los presentes. Caminar otra milla es también un ejemplo referido a las legiones romanas, que eran quienes medían en millas. De nuevo, que un campesino judío se ofreciera a 
caminar una milla más para transportar el equipo del ejército romano contradecía lo que las mismas ordenanzas romanas permitían exigir, y ponía a los soldados en un aprieto. En todos los casos, por tanto, se trata de introducir un comportamiento distinto, que tanga por resultado la introducción de una novedad, el cuestionamiento de la lógica opresiva, y la concesión de una oportunidad al opresor para reflexionar sobre su propio comportamiento.

5) En todo ello detectamos también lo que hemos Ilamado la "responsabilidad universal". Una responsabilidad universal que pasa, con todo, por la existencia de un pueblo que se comporta de modo distinto. Sin embargo, este comportamiento distinto se caracteriza precisamente por una apertura universal. Lo que caracteriza a otros pueblos es precisamente la diferencia entre "ellos" y "nosotros". Esta diferencia puede asumir distintas formas, entre las que se incluye el racismo, la xenofobia, y el mero nacionalismo. La simple idea de ciudadanía implica la distinción entre los que son ciudadanos de un determinado estado, y los que no lo son. Jesús, en cambio, manteniéndose dentro de las tradiciones judías, subraya la concepción de Israel como un pueblo universal, cuya radical distinción con los demás pueblos no está en determinadas características culturales o étnicas, sino precisamente en su universalidad.
El amor a los enemigos implica una diferencia radical con otros pueblos, pero una diferencia que consiste en no hacer diferencias. De este modo, Jesús asume y radicaliza la misión universal de Israel.

Observemos que, en todo ello, el pacifismo cristiano asume una perspectiva muy concreta: la perspectiva de los oprimidos. El que carga una milla con las vituallas del ejército romano, el que es requerido en juicio a entregar hasta su ropa, el que es golpeado con el reverso de la mano, no es el sacerdote que se sienta en Jerusalén, ni el príncipe judío que administra un estado vasallo. Son los pequeños, los humillados y los ofendidos. Mientras que la perspectiva de la ética de la responsabilidad, como hemos visto, es la del político y, en general, la de los poderosos, la perspectiva de Jesús es la de los más pequeños. Quienes invitan a la guerra, o a la revolución, no son normalmente quienes mueren en los campos de batalla, o en las aldeas bombardeadas. El pacifismo de Jesús no adopta el punto de vista de los intelectuales o los clérigos belicosos, sino el punto de vista de aquellos que sufren la violencia institucionalizada de los sistemas sociales y políticos. Con ellos, Jesús asume la vieja tarea de Israel de proponer una alternativa universal, para toda la humanidad. De ahí la originalidad, y la radicalidad, de su "teología social". 


\section{Conclusión}

Nuestro recorrido por algunos de los problemas éticos planteados por la diferencia entre la ética de la convicción y la ética de la responsabilidad nos ha permitido reflexionar sobre algunos de los problemas filosóficos y teológicos planteados por el pacifismo en general, y por el pacifismo de Jesús en particular. El pacifismo no tiene por qué consistir en una convicción irresponsable, sino que entraña altas formas de responsabilidad: la responsabilidad humanista, la responsabilidad alternativa, la responsabilidad anticipatoria, la responsabilidad poliárqui$\mathrm{ca}$, y la responsabilidad universal. A diferencia de otras éticas presuntamente responsables, el pacifismo entraña una radical universalidad. Esta universalidad no tiene por qué ser una universalidad abstracta. En el caso concreto de Israel, tal como Jesús lo interpreta, la universalidad pasa por la existencia de un pueblo concreto que, sin embargo, es un pueblo universal. No obstante, este pueblo apela especialmente, no a los fundadores (violentos o pacíficos) de nuevos estados, sino a los que sufren usualmente la violencia. Por eso, el pacifismo en general, y el pacifismo de Jesús en particular, constituyen posiciones especialmente relevantes en un tiempo caracterizado por el particularismo, la opresión, y la violencia.
Nos decía Max Weber que la ética de la convicción se desentiende de las consecuencias de la propia acción, dejándolas en las manos de Dios. Hemos visto que esto no es así. El pacifismo es, o puede ser, una convicción responsable. No obstante, el pacifismo cristiano tiene una dimensión explícitamente creyente. La idea de un "reino de Dios" implica, en definitiva, la confianza en que Dios rige la historia humana. Precisamente es la confianza en Dios lo que conduce, ya en el Antiguo Testamento, a la reducción de los ejércitos. Esta confianza no se refiere a las consecuencias previsibles de las propias acciones, respecto a las cuales el pacifista es responsable. La confianza se refiere a las consecuencias no previsibles de nuestras acciones. $Y$ no es necesario apelar a las teorías científico-filosóficas del caos para darse en cuenta de que, en la historia humana, la mayor parte de las consecuencias de nuestras acciones son imprevisibles. Precisamente por eso, la fe tiene siempre una constitutiva eficacia, pues es ella precisamente la que permite iniciar aquellos comportamientos que, sin la seguridad de lo previsible, nunca serían realizados. También en este sentido, la fe mueve montañas.

Antonio González San Salvador - Hoyo de Manzanares 2012 